\title{
Contribuições das teorias institucionais para o estudo de subsidiárias de corporações multinacionais
}

\section{Contributions of the Institutional Theories for the Study of Subsidiaries of Multinational Corporations}

\author{
Takeyoshi Imasato \\ Ana Lucia Guedes²
}

\section{Resumo}

Este ensaio destaca, inicialmente, as contribuições dos Estudos Organizacionais para o entendimento das corporações multinacionais. Em decorrência da capacidade de influenciar os demais atores nos âmbitos local, nacional, regional, internacional e transnacional, as multinacionais desafiam as abordagens tradicionais de estudos organizacionais seguidas por pesquisadores da área de Gestão Internacional. A seguir, o ensaio explora as possibilidades e os limites das abordagens de teoria institucional para o entendimento das subsidiárias de corporações multinacionais. Esse aporte teórico pode auxiliar tanto no estudo dessas empresas quanto da natureza das diferenças entre as instituições nos diversos países de operação, por possibilitarem a análise simultânea de múltiplos contextos institucionais simultaneamente. Como resultado, o ensaio contribui para o desenvolvimento teórico das interfaces entre as áreas de Estudos Organizacionais e de Gestão Internacional, principalmente, no que se refere às investigações que enfatizem o papel estratégico das subsidiárias.

Palavras-chave: relação matriz-subsidiária; gestão internacional; estudos organizacionais; teoria institucional.

\section{Abstract}

This paper emphasizes, initially, the contributions of Organizational Studies for the understanding of multinational corporations. As a result of the capacity to influence others actors in local, national, regional, international, and transnational contexts, the multinational corporations challenge the traditional approaches of Organizational Studies that are followed by researchers in the International Management field. As follows, the paper explores the possibilities and limits of the approaches of institutional theory for the understanding of multinational corporations' subsidiaries. This theoretical approach can assist on the study of these corporations as much as on the nature of the differences among institutions in the diverse countries of operation because it allows the simultaneous analysis of multiples institutional contexts. As result, this paper contributes to the theoretical development of the interfaces between the Organizational Studies and International Management fields, in what regards inquiries that emphasize the strategic role of subsidiaries.

Key words: headquarters-subsidiaries relationship; international management; organizational studies; institutional theory.

\footnotetext{
1 Doutorando da Escola Brasileira de Administração Pública e de Empresas da Fundação Getulio Vargas (EBAPE/FGV). Endereço: Praia de Botafogo, 190 - sala 538 - Botafogo - Rio de Janeiro - RJ - CEP.: 22250-900 - Brasil. E-mail: tkimasato@gmail.com

2 Professora Adjunto da Escola Brasileira de Administração Pública e de Empresas (EBAPE) da Fundação Getúlio Vargas (FGV), Rio de Janeiro, Brasil. Coordenadora do Grupo de Estudos Internacionais da EBAPE/FGV. Ph.D em Relações Internacionais, London School of Economics and Political Science (LSE), Inglaterra.Associate Professor, Brazilian School of Public Administration and Business, Getulio Vargas Foundation, Rio de Janeiro, Brazil. Chair of the International Studies Research Group at EBAPE/FGV. Ph.D. in International Relations, London School of Economics and Political Science (LSE), England. Praia de Botafogo, 190 sala 511, Rio de Janeiro-RJ, Brasil CEP 22250-900 - E-mail: ana.guedes@fgv.br
} 


\section{Introdução}

Pesquisadores e acadêmicos do âmbito de gestão internacional (GI) têm debatido acerca da definição do domínio da disciplina em termos de pesquisa e de produção de conhecimento (BODDEWYN, 1999; BODDEWYN; TOYNE; MARTÍNEZ, 2004; CONTRACTOR, 2000; MARTÍNEZ; TOYNE, 2000). Uma das justificativas para esse debate é a institucionalização relativamente recente da área. A International Management Division (IMD) da Academy of Management (AoM) surgiu na década de 1970. O currículo nas escolas de negócios demorou a ser atualizado e foi "internacionalizado" a partir da década de 1980 (CONTRACTOR, 2000). Em outras palavras, a área tem pouco mais de três décadas de existência nos Estados Unidos da América (EUA).

No Brasil, a área de GI constitui-se como divisão temática autônoma no Encontro da Associação Nacional de Pós-Graduação e Pesquisa em Administração (EnANPAD), principal congresso acadêmico em administração do país, no ano de 2001. Portanto, o processo de institucionalização da área é ainda mais recente no contexto brasileiro.1

Há uma dificuldade de definição do domínio da área, que pode ser atribuído à inexistência de uma fronteira clara que diferencie GI do âmbito de Negócios Internacionais (NI). Cabe destacar, por exemplo, que a Academy of International Business (AIB) foi criada em 1959 nos EUA. As sobreposições de interesses de pesquisa entre essas áreas (CONTRACTOR, 2000) tornam dispendiosas e pouco elucidativas as tentativas de diferenciação nos EUA, o que conseqüentemente tem sido reproduzido por pesquisadores de diversos países.

Uma forma de contornar tais dificuldades é ampliar a definição do âmbito de GI: como o da gestão das organizações que ultrapassam as fronteiras dos Estados nacionais (BODDEWYN; TOYNE; MARTÍNEZ, 2004; MARTÍNEZ; TOYNE, 2000). Dessa forma, práticas de gestão consideradas internacionais não se restringem ao contexto socioeconômico e cultural de determinado país. GI estaria, nessa linha de raciocínio, necessariamente vinculada ao estudo de práticas de gestão que afetam simultaneamente as ações organizacionais em vários países. Ao ultrapassar as fronteiras nacionais, lidando assim com a gestão de e entre contextos de países distintos, a área delimita um campo específico de atuação em administração. 2

Como conseqüência de tal definição de escopo, um tipo de organização se encaixa como locus de pesquisa privilegiado: as corporações multinacionais (GEPPERT; MATTEN; WALGENBACH, 2006; MORGAN; KRISTENSEN, 2006; ROTH; KOSTOVA, 2003; WESTNEY; ZAHEER, 2001). Por atuarem em vários países ao mesmo tempo e possuírem poder econômico e considerável influência política nos países de origem e de operação, especialmente no presente contexto de globalização (COWLING; TOMLINSON, 2005), as multinacionais constituem um objeto de estudo privilegiado, tanto para a área de GI quanto para a de NI.

Contudo, a compreensão das corporações multinacionais, tanto na literatura de NI quanto na de GI, é dominada por bagagens teóricas ortodoxas provenientes da economia (WESTNEY; ZAHEER, 2001). A preponderância das abordagens econômicas na construção de conhecimentos nessas áreas (ACEDO; CASILLAS, 2005) é reforçada pela resistência histórica e pelo baixo interesse de acadêmicos da área de Estudos Organizacionais (EO) de investigar as corporações multinacionais como uma forma organizacional distinta e relevante (BARLEY, 2007; MORGAN; KRISTENSEN, 2006; WESTNEY; ZAHEER, 2001).

Para evitar as sobreposições das áreas de GI e NI no que se refere ao estudo das corporações multinacionais, acadêmicos de GI buscaram aportes teóricos dos EO para operacionalizar a construção de uma distinção entre essas áreas. A teoria contingencial - referencial teórico dominante na academia de administração dos EUA na década de 1980 - foi a primeira abordagem adotada nos estudos de GI (DOZ; BARTLETT; PRAHALAD, 1981; DOZ; PRAHALAD, 2001). Contudo, esse esforço não foi profícuo para abalar o domínio das abordagens econômicas no estudo das corporações multinacionais.

O aporte teórico de EO adotado para a compreensão das multinacionais que tem buscado desafiar abordagens econômicas ortodoxas nos últimos anos é oriundo da teoria institucional (DAHAN; DOH; GUAY, 2006; GEPPERT; MATTEN; WALGENBACH, 2006; MORGAN; KRISTENSEN, 2006; WESTNEY, 2005). Os autores deste ensaio argumentam que a teoria institucional pode contribuir para a compreensão dos contextos 
institucionais em que as corporações multinacionais atuam, elucidando a possibilidade de construção de diferenciais competitivos (MORGAN; WHITLEY, 2003), bem como a compreensão dos mecanismos de pressões para conformação às regras institucionais locais e globais que afetam (tanto favorável quanto desfavoravelmente) as práticas e estratégias das multinacionais (WESTNEY, 2005).

Dessa forma, as contribuições deste ensaio podem ser organizadas em torno de três objetivos. Em primeiro lugar, o ensaio enumera os motivos pelas quais corporações multinacionais podem e devem ser adotadas como objeto de estudo de acadêmicos de EO. Os autores mostram que as multinacionais, por terem capacidade de influência nos âmbitos local, nacional, regional, internacional e transnacional, desafiam teorias fundamentadas em abordagens tradicionais de EO. Em segundo lugar, o ensaio explora as possibilidades e os limites da teoria institucional para a compreensão das corporações multinacionais. Por atuarem em múltiplos contextos institucionais, esse aporte teórico pode auxiliar, ainda que com limitações, no estudo da natureza das diferenças das instituições nos distintos contextos de atuação. Em terceiro lugar, e como conseqüência dos dois primeiros objetivos, o ensaio contribui para o desenvolvimento teórico das interfaces entre as áreas de EO e GI, principalmente, no que diz respeito às investigações que problematizem o caráter estratégico das subsidiárias.

\section{Estudos organizacionais e corporações multinacionais}

Alguns questionamentos, segundo Roth e Kostova (2003), são essenciais para estudos centrados nas corporações multinacionais: $\mathrm{O}$ que torna às corporações multinacionais um tipo de organização distinto? Que tipo de contribuição o estudo dessas organizações pode fornecer para a construção de teorias?

A presença de subsidiárias em múltiplos países é uma característica básica desse tipo de organização. Mais especificamente, a característica fundamental dessas organizações é possuir investimentos externos diretos em mais de um país (WILKINS, 2001). Esses investimentos permitem a internacionalização das empresas, e, por conseguinte, a criação de conexões regulares da empresa que ultrapassam as fronteiras nacionais dos países de origem.

Alguns dos tópicos de pesquisas contemporâneas em gestão relacionados às corporações multinacionais estão focados na complexa relação que existe entre matrizes e subsidiárias (BIRKINSHAW, 1997; GEPPERT; MATTEN; WALGENBACH, 2006). A organização interna das multinacionais se torna fundamental na operacionalização das práticas de gestão além das fronteiras nacionais. Gestão e transferência de conhecimentos, diferenças culturais dentro da corporação, processo de tomada de decisões e formulação de estratégias são algumas das linhas de pesquisas que levam em conta, direta ou indiretamente, aspectos ligados às práticas de gestão entre matriz e subsidiárias.

A literatura que contempla o estudo das subsidiárias de corporações multinacionais pode ser dividida em quatro linhas de pesquisa (BIRKINSHAW, 2001):

1. linha de pesquisa da estratégia-estrutura - que foca na estratégia e estrutura das multinacionais de uma perspectiva hierárquica, dando ênfase à compreensão da adoção de certas estruturas organizacionais por parte da multinacional, onde pouca atenção explícita era dada às subsidiárias;

2. linha de pesquisa da relação matriz-subsidiária - que busca determinar as formas como as matrizes podem controlar suas subsidiárias, na qual centralização e formalização são temas essenciais;

3. linha de pesquisa do processo da corporação multinacional - que mostra o poder relativo de matrizes diante das suas subsidiárias, mas ainda utiliza como unidade de análise a multinacional como um todo; $\mathrm{e}$

4. linha de pesquisa do papel da subsidiária - que identifica os diferentes papéis que as subsidiárias assumem na multinacional; portanto, mostra que as subsidiárias possuem graus de liberdade para direcionarem seu futuro, não sendo apenas meros instrumentos da matriz. 
A figura 1 ilustra as perspectivas e os conteúdos dessas quatro linhas de pesquisa. O eixo horizontal mostra o foco de análise da vertente, podendo enfatizar a multinacional como um todo ou parcialmente através das subsidiárias. Por meio do eixo vertical, que foca a hierarquia ou heterarquia3, observa-se que as vertentes estratégia-estrutura e relação matriz-subsidiária têm grande preocupação em analisar o tipo de relação hierárquica e os mecanismos de controle que a matriz se utiliza para controlar as suas subsidiárias. Essas duas vertentes resultam de uma visão tradicional de hierarquia, na qual a figura da matriz centralizadora e controladora é prescrita como necessária. As outras duas vertentes, processos das corporações multinacionais e papel da subsidiária, buscam relativizar essa necessidade de controle absoluto sobre as subsidiárias, mostrando que há graus de liberdade para ações autônomas por parte das subsidiárias.

Figura 1

Linhas de pesquisa com foco nas corporações multinacionais

\begin{tabular}{|r|c|c|}
\cline { 2 - 3 } Hierarquia & $\begin{array}{c}\text { Vertente da } \\
\text { estratégia- } \\
\text { estrutura }\end{array}$ & $\begin{array}{c}\text { Vertente da } \\
\text { relação matriz- } \\
\text { subsidiária }\end{array}$ \\
\cline { 2 - 3 } rede & $\begin{array}{c}\text { Vertente do } \\
\text { processo das } \\
\text { corporações } \\
\text { multinacionais }\end{array}$ & $\begin{array}{c}\text { Vertente do } \\
\text { papel da } \\
\text { subsidiária }\end{array}$ \\
\cline { 2 - 3 } & Todo & Parte \\
\hline
\end{tabular}

Fonte: adaptado de Birkinshaw (2001, p.382).

Essas duas linhas de pesquisa sustentam que as subsidiárias não têm um mesmo tipo de atividade a desempenhar ou uma mesma importância em relação à matriz da corporação multinacional. Algumas são mais necessárias e têm mais peso para a estratégia e desempenho das corporações do que outras. Para conseguir visualizar melhor tal diferenciação entre subsidiárias, Bartlett e Ghoshal (1989) propõem uma tipologia com quatro tipos de subsidiárias:

1. líderes estratégicos são unidades importantes que estão localizadas em países de importância crítica, sendo imprescindíveis para a corporação;

2. contribuidores possuem capacidades de competição diferenciadas no seu contexto de atuação, mas estão localizadas em mercados menos importantes para a corporação;

3. implementadores não possuem capacidades organizacionais diferenciadas diante da concorrência local e estão em mercados de pouca importância para a corporação, e

4. buracos negros estão em países ou regiões essenciais, mas possuem poucas competências organizacionais para competir no contexto em que atuam.

Independentemente da tipologia utilizada para a classificação de subsidiárias, 4 os processos de formação da noção de importância das subsidiárias em relação a suas matrizes ainda são pouco conhecidos e/ou sistematicamente estudados. Há aspectos relacionados à tomada de decisões e ao processo de negociação entre matrizes e subsidiárias, e também à forma específica de atuação nos diferentes mercados, que, por exemplo, 
ainda carecem de compreensão (DÖRRENBÄCHER; GAMMELGAARD, 2006; MORGAN; WHITLEY, 2003).

A construção da importância estratégica da subsidiária em relação aos interesses e objetivos estratégicos da matriz não ocorre necessariamente de forma unilateral, como uma imposição da matriz às suas subsidiárias. Subsidiárias também podem, por meio de ações autônomas, influenciar e conquistar maior importância estratégica em relação à matriz pelo desenvolvimento de novos produtos e serviços competitivos para a corporação (BIRKINSHAW, 1997; BIRKINSHAW; MORRISON, 1995). Dessa forma, a subsidiária aumenta sua capacidade de barganha, podendo influenciar a formulação de estratégias da corporação (DÖRRENBÄCHER; GAMMELGAARD, 2006; TREGASKIS, 2003). Esse tipo de abordagem dinâmica indica que há espaços para agência por parte das subsidiárias e isso torna mais difícil uma abordagem estática de classificação de subsidiárias.

No entanto, não é apenas a configuração interna do planejamento e controle das atividades intraorganizacionais das corporações multinacionais que merecem mais atenção por parte dos pesquisadores da área de GI. No processo, recentemente intensificado, de globalização, corporações multinacionais passaram a manter o domínio de mercados em diversos setores (COWLING; TOMLINSON, 2005). Essa é outra face das multinacionais. O poder econômico e político que esse tipo de organização conquistou e exerce nos países em que atua resulta em impactos consideráveis, especialmente, para países economicamente menos desenvolvidos e dependentes dessas empresas para fins de desenvolvimento (HODGE; CORONADO, 2006).

Um exemplo dessa concentração oligopolista pode ser observado nos mercados internacionais de commodities. Cowling e Tomlinson (2005) estimaram que três a seis das maiores multinacionais controlam $85 \%$ a $90 \%$ do mercado mundial de café, $85 \%$ do mercado de sementes de cacau, $85 \%$ a $90 \%$ do mercado de juta e $75 \%$ a $85 \%$ do mercado de estanho.

Segundo Anderson e Cavanagh (2000), excluindo-se as dez maiores economias nacionais, a combinação das vendas das 200 maiores corporações, no ano de 1999, foi maior do que a soma das economias de todas as demais nações do mundo nesse ano. Além disso, apesar das vendas das 200 maiores empresas terem sido equivalentes a algo em torno de $27 \%$ da atividade econômica mundial desse ano referido, elas foram responsáveis por apenas $0,78 \%$ dos empregos ofertados no mundo. O que torna esses dados ainda mais incisivos é que no ranking das 100 maiores economias mundiais em 1999, 51 eram corporações e 49 representavam países.

O poder econômico das corporações multinacionais se materializa principalmente em produtos e serviços que são comercializados e consumidos no dia-a-dia. Como resultado da concentração de mercados, as corporações se tornaram responsáveis pelos principais produtos ofertados no mundo e, sobretudo, dominam as marcas associadas a esses bens (KLEIN, 2000).

Cabe ressaltar que essas marcas não representam mais apenas meros atributos físicos ou técnicos dos produtos ou serviços. Tais marcas envolvem cada vez mais elementos simbólicos (KLEIN, 2000). Na medida em que o ato de saciar necessidades cotidianas é simbolizado por meio das corporações e seus produtos, constrói-se certa dependência em relação a elas. Em outras palavras, o poder simbólico das marcas resulta em um relacionamento de dominação e dependência.

Em resumo, a complexidade interna na coordenação e gestão e a sua capacidade de influência econômica e política nos contextos sociopolíticos em que atuam tornam as corporações multinacionais um campo profícuo para pesquisa e construção de conhecimento acadêmico, tanto para a área de GI quanto para a de EO. As corporações têm a capacidade de influenciar organizações, políticas e instituições nos contextos local, nacional, regional, internacional e transnacional em que atuam, desafiando teorias fundamentadas em abordagens tradicionais de EO (BARLEY, 2007; GHOSHAL; WESTNEY, 2005; STERN; BARLEY, 1996). Essas abordagens tradicionais têm carecido, por exemplo, de teorizações a respeito da dimensão política relacionadas às corporações multinacionais (BARLEY, 2007; DAHAN; DOH; GUAY, 2006; GEPPERT; MATTEN; WALGENBACH, 2006). De fato, a dimensão política das organizações merece mais 
desenvolvimento teórico na área de GI e isso justifica a proposta dos autores deste ensaio de promover a aproximação entre as áreas de EO e GI.

\section{As múltiplas abordagens de teorias institucionais}

Uma das abordagens teóricas que tem sido utilizada para analisar corporações multinacionais como fenômeno organizacional mais complexo é a teoria institucional (GEPPERT; MATTEN; WALGENBACH, 2006; MORGAN; WESTNEY; ZAHAAER, 2001; WHITLEY, 2003). Cabe destacar que seria inadequado tratá-la no singular, como "a teoria", visto que existem múltiplas abordagens institucionais.

Nas últimas duas décadas, os trabalhos com análises institucionais têm se baseado em literaturas conhecidas como "novo institucionalismo". O novo institucionalismo tem três variações diferentes:

1. institucionalismo da decisão racional ou institucionalismo econômico, de orientação centrada na economia, que utiliza as transações como unidade central responsável pela formação de mercados, hierarquias e organizações;

2. institucionalismo histórico ou institucionalismo comparativo histórico, de orientação política, que parte da análise das estruturas sociais, econômicas e políticas existentes em um dado contexto para vislumbrar padrões ou regularidades nos processos de interações sociais para que, com isso, seja possível elaborar comparações entre diferentes contextos políticos e econômicos; e

3. institucionalismo sociológico ou institucionalismo organizacional, de orientação sociológica, que busca compreender como regras e normas socialmente construídas moldam os indivíduos e organizações (CAMPBELL, 1997; CARVALHO; VIEIRA, 2003; CARVALHO; VIEIRA; GOULART, 2005; HALL; TAYLOR, 1996; THELEN, 1999).

A abordagem da orientação econômica tem sido uma fonte menos utilizada pelos acadêmicos de GI nos estudos focados em corporações multinacionais.5 Isso se deve ao apego dessa perspectiva às transações como unidade de análise fundamental. A literatura dominante (e predominantes na área de NI) dessa vertente argumenta que é por meio de transações que as organizações, os mercados e as instituições se formam. Porém, há outras interações e relações entre organizações que não são meramente regidas por contratos. A concepção de racionalidade dessa abordagem - que interpreta as organizações como meros substitutos estruturais para fins de transações eficientes onde o mercado falha - limita a própria compreensão do que são organizações e por quais tipos de práticas sociais elas se reproduzem, disseminam e se extinguem (GHOSHAL; MORAN, 1996).

A orientação sociológica tem sido utilizada para estudar o fenômeno da "dualidade institucional" (KOSTOVA; ROTH, 2002) na adoção de práticas organizacionais pelas subsidiárias. A dualidade institucional se refere ao estudo, em multinacionais, das pressões isomórficas6 exercidas pela matriz, por um lado, e por outro, pelo contexto institucional do país no qual a subsidiária está localizada. A ênfase dessa dualidade é relevante porque, no atual estágio de internacionalização das corporações multinacionais, a concepção tradicional de isomorfismo pode ser considerada frágil e até mesmo problemática (DELMESTRI, 2006; WESTNEY, 2005).

Os primeiros trabalhos privilegiaram o estudo de como subsidiárias se adequavam aos anseios da matriz, na qual há um processo de conformação passiva (ROSENZWEIG; SINGH, 1991). Trabalhos contemporâneos, porém, buscam contextualizar o processo de homogeneização de práticas de forma menos passiva, na qual a subsidiária tem possibilidades de lidar com as pressões (FERNER; ALMOND; COLLING, 2005; GEPPERT; WILLIAMS; MATTEN, 2003; KOSTOVA; ROTH, 2002; MORGAN; KRISTENSEN, 2006). Assim, considera-se que as práticas das subsidiárias não são construções meramente reativas, que são impostas e simplesmente aceitas. Há espaço para manobras ou escolhas estratégicas por parte das subsidiárias (FERNER; ALMOND; COLLING, 2005), ainda que a abordagem seguida pela maior parte dos autores tenha conotação predominantemente adaptativa.

As subsidiárias podem balancear as pressões da matriz e do contexto local. Esse processo denota a existência de negociações e conflitos entre a matriz e as subsidiárias, que, ao abrirem uma multiplicidade de futuras escolhas 
estratégicas, podem direcionar e moldar o destino das decisões, estratégias e práticas de gestão no âmbito da subsidiária (MORGAN; KRISTENSEN, 2006). Esse processo de negociação tem sido chamado em alguns trabalhos mais recentes de "micropolítica" (DÖRRENBÄCHER; GAMMELGAARD, 2006; GEPPERT; WILLIAMS; MATTEN, 2003; MORGAN; KRISTENSEN, 2006).

O institucionalismo histórico tem ampliado seu escopo no estudo das corporações multinacionais nos últimos anos. Com base na economia política, principal influência dessa variação da teoria institucional, esse institucionalismo busca, essencialmente, análises e comparações do processo de institucionalização em sistemas de negócios de contextos distintos (HALL; TAYLOR, 1996; WHITLEY, 1999). Em primeiro lugar, os autores focam suas análises nas instituições da sociedade que criam acesso aos recursos críticos, tais como capital e trabalho, que governam e moldam os sistemas de negócios de um país (GEPPERT; MATTEN; WALGENBACH, 2006). Visto que essas instituições formam os pilares sobre os quais operam as relações de trocas econômicas capitalistas, essas instituições expressam a essência das regularidades dos sistemas de negócios.

Outro ponto se refere à análise de instituições complementares que modelam as regras seguidas pelas organizações (MORGAN; KRISTENSEN, 2006). Mesmo operando sob as regras do capitalismo, e mesmo com a globalização econômica e seus impactos na economia global, os países ainda atribuem ênfases distintas às estruturas, práticas e processos que operacionalizam os sistemas econômicos. Isso gera a diversidade de instituições. Corporações multinacionais, ao cruzarem as fronteiras dos países de origem tendem a enfrentar tal diversidade. As instituições do país de origem e do país de operação da subsidiária usualmente são diferentes, mesmo entre países considerados desenvolvidos (HALL; SOSKICE, 2001). O estudo de corporações multinacionais, dessa perspectiva, passa pela compreensão da forma como elas respondem a essa diversidade em termos de estratégias e de práticas de gestão (MORGAN; KRISTENSEN, 2006).

Alguns autores alinhados ao institucionalismo histórico também advogam a utilização das três variações do institucionalismo para a análise comparativa dos sistemas de negócios. Eles enfatizam, entretanto, as variações sociológica e histórica. Essa orientação teórica tem sido conhecida como a abordagem da "variedade de capitalismos" (HALL; SOSKICE, 2001; WHITLEY, 1999). Utilizando firmas de países considerados desenvolvidos como unidade central de análise dos sistemas econômicos, na qual elas são responsáveis pela agregação de desempenho econômico dentro de um arranjo institucional de um país, comparações de mecanismos de coordenação que envolvem firmas, governos, organizações públicas e outros atores em certos contextos econômicos podem ser investigadas.

Trabalhos empíricos dessa variação de abordagem institucional demonstram que corporações adquirem capacidade para se adaptar, de forma que consigam atuar em múltiplos contextos, incorporando regras locais dos negócios, além de possuírem capacidade ativa para moldar as instituições locais (DAHAN; DOH; GUAY, 2006; GEPPERT; MATTEN; WALGENBACH, 2006; MORGAN; KRISTENSEN, 2006; TEMPEL et al, 2006). Corporações multinacionais, nessa perspectiva de análises comparativas, não têm poder incondicional para impor globalmente suas "best practices" por meio de suas subsidiárias - elas tanto moldam quanto são moldadas no processo.

Contudo, alguns autores ressaltam que as corporações têm poder para moldar práticas de gestão e até mesmo políticas públicas que se institucionalizam em vários contextos (BARLEY, 2007; STERN; BARLEY, 1996). Mesmo considerando as diferenças entre os países, alguns desses pesquisadores ressaltam as assimetrias de poder político que favorecem as corporações multinacionais (COWLING; TOMLINSON, 2005), especialmente, em países considerados menos desenvolvidos (HODGE; CORONADO, 2006).

\section{Múltiplas abordagens institucionais e o estudo das corporações multinacionais}

A complexidade administrativa interna que resulta das relações entre matriz e subsidiárias nas corporações multinacionais deve ser cuidadosamente avaliada nas práticas de pesquisa. Há conflitos e processos de negociação entre gestores da matriz e das subsidiárias que impõem e modificam as práticas organizacionais e as estratégias correspondentes em ambos os sentidos. $\mathrm{O}$ aprofundamento da compreensão dessa dinâmica carece 
de estudos específicos, apesar das reconhecidas dificuldades de acesso a esse tipo de fenômeno nas investigações empíricas (ver VAN MAANEN, 2005).

O poder político das corporações multinacionais, na sua potencialidade de moldar, alterar e influenciar as instituições políticas nos diversos contextos em que atuam, e o poder econômico, em que segmentos de mercados da economia mundial são por elas controlados, evidencia o desafio que essas organizações representam para as teorias organizacionais tradicionais (BARLEY, 2007; COWLING; TOMLINSON, 2005). Abordagens preocupadas com a construção de modelos de gestão não conseguem, por exemplo, capturar essa dimensão política de forma adequada (com raras exceções, como em Boddewyn, 1988, 1992; Hadjikhani, 2000). Essa dimensão política acaba sendo uma categoria acessória e não essencial nas teorias tradicionais em gestão que estudam corporações multinacionais, o que se mostra cada vez menos condizente com a posição de poder privilegiado desse tipo de organização (COWLING; TOMLINSON, 2005).

Cabem então os seguintes questionamentos: As teorias institucionais são capazes de capturar tal complexidade? Quais contribuições elas podem oferecer para a literatura de GI? O institucionalismo da decisão racional, como foi visto, tende a dar contribuições acessórias às interpretações das outras duas variações de teoria institucional. A sua intensa utilização nos últimos anos (principalmente na área de NI) mostra sinais de desgaste para contribuições específicas em GI. Além disso, essa abordagem enfrenta dificuldades para capturar a dimensão política.

A orientação sociológica, ao enfocar a dualidade institucional, pode contribuir para um melhor entendimento da dinâmica das pressões isomórficas exercidas pelas matrizes sobre as suas subsidiárias nos contextos locais de operação. O contexto social local é relevante na adoção de práticas de gestão por parte das subsidiárias. As matrizes das corporações podem não conseguir impor a adoção de certas práticas, mesmo que favorecidas pelo poder da autoridade, por encontrarem subsidiárias com capacidade de mobilizar os recursos das instituições do contexto local (MORGAN; KRISTENSEN, 2006). Isso pode ser interpretado como um ato de resistência por parte da subsidiária. Porém, pode ser também uma decisão estratégica consciente dos gestores da subsidiária que, por conhecerem melhor o contexto local, consideram a adoção de certas práticas oriundas da matriz danosas para a corporação, preferindo soluções construídas localmente (WESTNEY, 2005).

A análise do processo de isomorfismo em diferentes países pode possibilitar a comparação de contextos institucionais, identificando fragilidades (ou maior facilidade para alterar normas e regras de um contexto institucional) e forças (ou maior resistência para mudar essas normas e regras) entre as instituições dos países em questão. Esse enfoque mostra o potencial da utilização conjunta de teorias institucionais (HALL; SOSKICE, 2001).

Um dos pontos que ainda merece atenção por parte dos estudos focados na dualidade institucional é verificar se a matriz pode ser considerada uma instituição do ponto de vista das subsidiárias. Não há dúvidas de que a matriz exerce pressões para a conformação das subsidiárias. Contudo, para que seja uma instituição, há a necessidade de que os processos sociais em questão tenham status de regras ou normas tidas como dadas7 (MEYER; ROWAN, 1977). Neste ponto, cabem os seguintes questionamentos: (a) a corporação multinacional é uma instituição per se?; (b) as pressões da matriz são reflexos do contexto institucional do país de origem?, e (c) nesse sentido, a matriz é um meio pelo qual as pressões transpõem contextos e se internacionalizam?

Outra possibilidade de estudo focada no institucionalismo sociológico seria pela análise das pressões isomórficas que a subsidiária, por exemplo, causa no contexto local em que atua. Os estudos têm privilegiado o estudo dos processos isomórficos das subsidiárias nos países de operação, mas pouco se verificou sobre pressões isomórficas que subsidiárias, como representantes da multinacional, impõem nas práticas políticas, econômicas, ambientais, culturais, sociais e de ensino onde se instalam.

Os dois pontos levantados anteriormente podem ser ilustrados pela aprovação da lei Sarbanes-Oxley nos EUA. Como resposta aos escândalos gerenciais e contábeis gerados por corporações como a Enron e a WorldCom, o congresso americano aprovou, em 2002, a lei conhecida como Sarbanes-Oxley, que impõe novas diretrizes para o controle contábil e a realização de auditorias para as empresas que operam sob a jurisdição dos EUA. As pesadas penalidades que foram prescritas fizeram com que as empresas rapidamente buscassem se adequar a 
essa nova lei. Pesquisas e reflexões acerca dos impactos das pressões normativas dessa nova lei no sistema contábil no contexto daquele país foram realizadas por meio de abordagens alinhadas ao institucionalismo sociológico (ver BAKER et al, 2006; BEALING; BAKER, 2006). Porém, as implicações dessa mudança não se restringiram apenas às empresas localizadas dentro das fronteiras geográficas dos EUA: todas as subsidiárias no exterior das empresas submetidas à legislação americana também precisam estar em conformidade com a nova lei. As pressões normativas desse tipo de isomorfismo, desse modo, podem transcender e transitar entre diferentes contextos (ver DELMESTRI, 2006). A pesquisa da dinâmica das pressões causadas por essa lei para a gestão das subsidiárias no exterior, por exemplo, ainda é incipiente, sendo um potencial objeto de análise para compreensão da transposição de pressões isomórficas entre países. 8

O institucionalismo histórico pode ser desenvolvido por meio de estudos que explorem a influência política que corporações multinacionais exercem em diversos locais onde atuam (DAHAN; DOH; GUAY, 2006; GEPPERT; MATTEN; WALGENBACH, 2006), em que subsidiarias podem adquirir e incorporar uma importância estratégia diante de sua matriz. Uma forma de influência se dá por meio de estratégias e ações que envolvam o Estado, organizações internacionais e as multinacionais (HODGE; CORONADO, 2006; WESTNEY, 2005).

As corporações multinacionais podem influenciar ativamente na formulação de políticas de comércio exterior por meio da formação, por exemplo, de redes que busquem assegurar o alinhamento de políticos e tomadores de decisão de políticas públicas com os seus interesses (DAHAN; DOH; GUAY, 2006). Um exemplo disso é a rede de corporações chamada Transatlantic Business Dialogue,9 formada por grandes multinacionais, que, além dos esforços por uma maior liberalização do comércio, também trabalham para que haja uma "cooperação regulatória" entre os EUA e a União Européia. Essas ações corporativas exemplificam a necessidade de se atentar para a influência política dessas grandes corporações, pois as

grandes corporações multinacionais ganharam um grau de influência política que levanta sérios questionamentos quanto à transparência e à legitimidade do papel da corporação na moldagem de instituições que governam a economia global, regulação e processos políticos. (GEPPERT; MATTEN; WALGENBACH, 2006, p.1459)

A combinação das três variações de teoria institucional pode auxiliar na compreensão e comparação das trajetórias distintas de formação das instituições dos países analisados. Em um contexto internacional caracterizado pela globalização, corporações multinacionais tendem à concentração de certos mercados e à oligopolização das transações entre países (COWLING; TOMLINSON, 2005). A utilização combinada de teorias institucionais pode favorecer a compreensão dos mecanismos utilizados pelas corporações para estruturarem políticas, estratégias e práticas organizacionais no intuito de manter a influência sobre diversas instituições nos âmbitos social, político e econômico (GEPPERT; MATTEN; WALGENBACH, 2006). Além disso, podem colaborar para a análise da diferenciação do caráter estratégico das subsidiárias em diferentes contextos.

As variações de institucionalismo, entretanto, apresentam visões e definições distintas sobre significados de instituição e de como se dá o processo de institucionalização de práticas sociais (HALL; TAYLOR, 1996), requerendo uma atenção conceitual e metodológica dos pesquisadores que buscam seguir esse tipo de análise combinada. A possibilidade de serem tratadas e utilizadas em conjunto ainda necessita ser explorada e esclarecida. Pode haver incomensurabilidade entre as variações de institucionalismo (ver JACKSON; CARTER, 1991). Contudo, é preciso explorar se tais incomensurabilidades existem e se possíveis soluções para tais restrições teóricas podem ser encontradas, para que se avance no desenvolvimento teórico (WEAVER; GIOIA, 1994).

Cabe salientar, por fim, a grande influência da ciência positiva e do funcionalismo nas variações de teorias institucionais apresentadas (BOWERING, 2000; HAY; WINCOTT, 1998). A concepção de ação corre o risco de se tornar meramente adaptativa e reativa à estrutura existente, na qual há pouco ou nenhum espaço para ações estratégicas dos atores. A homogeneização de estruturas e processos pode tomar conta das análises, dificultando a compreensão do surgimento de um cenário novo, com suas respectivas alterações nas configurações de poder e de interesses em um dado campo (CARVALHO; VIEIRA; GOULART, 2005). Ainda 
mais danoso, porém, pode ser a reificação das "organizações" e do "ambiente institucional" que, ao serem creditados pelos atributos que na realidade são dos atores que os compõem ou moldam, retiram dos atores a capacidade de ação (BOWERING, 2000).

Essas ressalvas são importantes na medida em que o que se pretende, por meio da combinação das teorias institucionais, não é levantar apenas o motivo pelo qual há a (re)produção de formas organizacionais similares, que o institucionalismo sociológico sistematicamente levantou nos últimos anos. Pesquisas em GI precisam avançar na compreensão de ações autônomas (RUGMAN; VERBEKE, 2003), onde a capacidade de formulação de estratégias por parte das subsidiárias se torna um elemento central (BIRKINSHAW, 2001). A combinação das teorias institucionais apresentadas pode colaborar para a compreensão das especificidades institucionais de cada contexto de operação das subsidiárias, mostrando como certos conhecimentos são circunscritos a determinados locais. Cabe ressaltar que a participação ativa dos gerentes dessas localidades seria indispensável na formulação de estratégias tanto no âmbito local quanto internacional (DELMESTRI, 2006).

\section{Considerações finais}

Este ensaio evidencia, com base nas reflexões de Westney (2005),10 o potencial de pesquisas que explorem a interface entre GI e EO por meio do uso combinado das três abordagens da teoria institucional - sociológica, histórica e econômica - para o desenvolvimento teórico de ambas as áreas. A abordagem da "variedade de capitalismos" (HALL; SOSKICE, 2001) também pode ser uma fonte de desenvolvimento teórico, apesar dos contextos dos países denominados de emergentes ainda não terem sido explorados, o que constitui uma lacuna na literatura.

Os autores deste ensaio sugerem que a aproximação entre as áreas de GI e EO é particularmente relevante para aprofundar a compreensão das operações e estratégias de subsidiárias de corporações multinacionais. $\mathrm{O}$ ensaio destaca, ao elaborar uma análise de possíveis interfaces entre as teorias institucionais e o estudo das corporações multinacionais, o caráter estratégico que pode ser exercido pelas subsidiárias das multinacionais.

O esforço de desenvolver as interfaces entre GI e EO faz mais sentido, para os autores deste ensaio, quando o caráter estratégico é enfatizado (ver BIRKINSHAW, 2001). A importância estratégica das subsidiárias emerge quando elas passam a ter certo grau de autonomia para a criação de valor para a corporação como um todo. Essa autonomia é concedida ou conquistada pelas subsidiárias quando é evidenciado que elas atuam em um contexto institucional distinto do da matriz, e que elas possuem condições para a tomada de decisões e para a gestão de ações de posicionamento de mercado e de desenvolvimento de recursos e vantagens para a organização.

As abordagens de teorias institucionais descritas e analisadas neste ensaio, portanto, podem colaborar tanto para o avanço teórico que evidencia a importância estratégica das subsidiárias (BIRKINSHAW, 2001; RUGMAN; VERBEKE, 2003) quanto para o desenvolvimento de contribuições para a teoria organizacional que, de modo geral, tem apenas oferecido subsídios para a área de GI e não tem recebido, em contrapartida, contribuições para o seu próprio desenvolvimento (GHOSHAL; WESTNEY, 2005).

Por fim, o atual poder das corporações multinacionais, em termos políticos e econômicos, sem precedentes na história, indica a magnitude do desafio que é analisá-las, compreendê-las e criticá-las. Este ensaio evidencia a relevância da inclusão da dimensão política nas análises, por mais gerencial que seja a preocupação e orientação de pesquisa adotada pelos pesquisadores da área. Os autores deste ensaio argumentam que incluir a dimensão política, por meio da aproximação das áreas de GI e EO, principalmente, no que se refere às contribuições do institucionalismo histórico, pode agregar robustez e profundidade para as pesquisas e para a geração de conhecimentos acadêmicos que sejam relevantes tanto para a área de GI quanto para a de EO. 


\section{Referências}

ACEDO, F. J.; CASILLAS, J. C. Current paradigms in the international management field: an author co-citation analysis. International Business Review, v.14, p.619-639, 2005.

ANDERSON, Sarah; CAVANAGH, John. The rise of corporate global power. Washington: Institute for Policy Studies, 2000. Disponivel em: <http://www.ips-dc.org/downloads/Top_200.pdf>. Acessado em: 20 dez. 2006.

BAKER, R. et al. An institutional perspective of the Sarbanes-0xley Act. Managerial Auditing Journal, v.21, n.1, p.23-33, 2006.

BARLEY, S.R. Corporations, democracy and the public good. Journal of Management Inquiry, v. 16, n. 3, p. 201-215, 2007.

BARTLETT, C. A.; GHOSHAL, S. Managing across borders: the transnational solution. Boston: Harvard Business School Press, 1989.

BEALING, W. E.; BAKER, R. The Sarbanes-0xley Act: have we seen it all before? Journal of Business \&t Economic Studies, v.12, n.2, p.1-10, 2006.

BIRKINSHAW, Julian. Entrepreneurship in multinational corporations: characteristics of subsidiary initiatives. Strategic Management Journal, v.18, n.3, p.207-229, 1997.

Strategy and management in MNE subsidiaries. In: RUGMAN, A. M.; BREWER, T. (Eds.). The Oxford handbook of international business. Oxford: Oxford University Press, 2001.

; MORRISON, Allen J. Configurations of strategy and structure in subsidiaries of multinational corporations. Journal of International Business Studies, v.26, n.4, p.729-753, 1995.

BODDEWYN, Jean. Political aspects of MNE theory. Journal of International Business Studies, v.19, n.3, p.341-363, 1988.

Political behavior research. In: BUCLEY, P. (Ed.). New directions in International Business: research priorities for the 1990's. Aldershot: Edward Elgar, 1992,

The domain of international management. Journal of International Management, v.5, p.3-14, 1999.

; TOYNE, B.; MARTÍNEZ, Z. The meaning of "international management". Management International Review, v.44, n.2, p.195-212, 2004.

BOWERING, Michéle A. De/Constructing theory: a look at institutional theory that positivism built. Journal of Management Inquiry, v.9, n.3, p.258-270, 2000.

CAMPBELL, John L. Recent trends in institutional political economy. International Journal of Sociology and Social Policy, v.17, n.7/8, p.15-56,1997.

CARVALHO, Cristina A.; VIEIRA, Marcelo M. F. Contribuições da perspectiva institucional para a análise das organizações: possibilidades teóricas, empíricas e de aplicação. In: CARVALHO, C. A.; VIEIRA, M. M. F. (Org.). Organizações, cultura e desenvolvimento local: a agenda de pesquisa do Observatório da Realidade Organizacional. Recife: Editora da UFPE, 2003.

$874,2005$.

; GOULART, Sueli. A trajetória conservadora da teoria institucional. Revista de Administração Pública, v.39, n.4, p.849-

CONTRACTOR, F. J. The raisons d'être for international management as a field of study. Journal of International Management, v.6, p.3$10,2000$.

COWLING, K.; TOMLINSON, P. Globalisation and corporate power. Contributions to Political Economy, v.24, p.33-5, 2005.

DAHAN, N.; DOH, J.; GUAY, T. The role of multinationals corporations in transnational institution building: a policy network perspective. Human Relations, v.59, n.11, p.1571-1600, 2006.

DELMESTRI, G. Streams of inconsistent institutional influences: Middle managers as carriers of multiple identities. Human Relations, v. 59, n. 11, p. 1515-1541, 2006.

DIMAGGIO, Paul J.; POWELL, Walter W. The iron cage revisited: institutional isomorphism and collective rationality in organizational fields. American Sociological Review, v.48, n.2, p. 147-160, 1983.

DÖRRENBÄCHER, C.; GAMMELGAARD, J. Subsidiary role development: the effect of micro-political headquarters-subsidiary negotiations on the product, market and value-added scope of foreign-owned subsidiaries. Journal of International Management, v.12, p.266-283, 2006.

DOZ; Y. L.; BARTLET, C.; PRAHALAD, C. K. Global competitive pressures versus host country demands: managing tensions in multinational corporations. California Management Review, v.23, n.3, p.63-74, 1981. 
; PRAHALAD, C. K. Managing MNCs: a search for a new paradigm. In: RUGMAN, A. M.; BREWER, T. (Ed.). The Oxford handbook of international business. Oxford: Oxford University Press, 2001.

FERNER, Anthony; ALMOND, Phil; COLLING, Trevor. Institutional theory and the cross-national transfer of employment policy: the case of 'workforce diversity' in US multinationals. Journal of International Business Studies, v.36, p.304-321, 2005.

GEPPERT, Mike; MATEN, Dirk; WALGENBACH, Peter. Transnational institution building and the multinational corporation: an emerging field of research. Human Relations, v.59, n.11, p.1451-1465, 2006.

; WILLIAMS, Karen; MATEN, Dirk. The social construction of contextual rationalities in MNCs: an Anglo-German comparison of subsidiaries choice. Journal of Management Studies, v.40, n.3, p.617-641, 2003.

GHOSHAL, S.; MORAN, P. Bad for practice: a critique of the transaction cost theory. Academy of Management Review, v.21, n.1, p.13-47, 1996.

; WESTNEY, D. E. (Ed.). Organization theory and the multinational corporation. $2^{\text {nd }}$ ed. Houndmills: Palgrave, 2005.

HADJIKHANI, A. The political behavior of business actors: the case of Swedish MNCs and EU. International Studies of Management and Organizations, v.30, n.1, p.93-117, 2000.

HALL, Peter A.; SOSKICE, David. An introduction to varieties of capitalism. In: HALL, P. A.; SOSKICE, D. (Ed.). Varieties of capitalism. Oxford: Oxford University Press, 2001.

; TAYLOR, Rosemary C. R. Political science and the three new institutionalism. Political Studies, v.44, p.936-957, 1996.

HAY, Colin; WINCOT, Daniel. Structure, agency and historical institutionalism. Political Studies, v.46, p.951-957,1998.

HODGE, Bob; CORONADO, Gabriela. Mexico Inc.? Discourse analysis and the triumph of managerialism. Organizations, v.13, n.4, p.529547, 2006.

JACKSON, N.; CARTER, P. In defense of paradigm incommensurability. Organization Studies, v.12, n.1, p.109-127, 1991.

KLEIN, Naomi. The tyranny of the brands. New Statesman, v.129, n.4470, p.25-28, 2000.

KOSTOVA, Tatiana; ROTH, Kendall. Adoption of an organizational practice by subsidiaries of multinational corporations: institutional and relational effects. Academy of Management Journal, v.45, n.1, p.215-233, 2002.

MARTÍNEZ, Zaida L.; TOYNE, Brian. What is international management, and what is it domain? Journal of International Management, v.6, p.11-28, 2000.

MEYER, J.; ROWAN, B. Institutionalized organizations: formal structure as myth and ceremony. American Journal of Sociology, v.83, n.2, p.340-363, 1977.

MORGAN, Glenn; KRISTENSEN, Peer H. The contested space of multinationals: varieties of institutionalism, varieties of capitalism. Human Relations, v.59, n.11, p.1467-1490, 2006.

; WHITLEY, Richard. Introduction. Journal of Management Studies, v.40, n.3, p.609-616, 2003.

ROSENZWEIG, Philip M.; SINGH, Jitendra V. Organizational environments and the multinational enterprise. Academy of Management Review, v.16, n.2, p.340-361, 1991.

ROTH, Kendall; KOSTOVA, Tatiana. The use of multinational corporation as a research context. Journal of Management, v.29, n.6, p.883902, 2003.

RUGMAN, A.; VERBEKE, A. Extending the theory of the multinational enterprise: internationalization and strategic management perspectives. Journal of International Business Studies, v.34, n.2, p.125-137, 2003

STERN, R.N.; BARLEY, S.R. Organizations and social systems: organization theory's neglected mandate. Administrative Science Quarterly, v. 41, p. 146-162, 1996.

TEMPEL, Anne et al. Subsidiary responses to institutional duality: collective representation practices of US multinationals in Britain and Germany. Human Relations, v.59, n.11, p.1543-1570, 2006.

THELEN, Kathleen. Historical institutionalism in comparative politics. Annual Review of Political Sciences, v.2, p.369-404, 1999.

TREGASKIS, Olga. Learning networks, power and legitimacy in multinational subsidiaries. International Journal of Human Resources Management, v.14, n.3, p.431-447, 2003. 
VAN MAANEN, J. Mickey on the move: observations on the flow of culture in the multinational corporation. In: GHOSHAL, S.; WESTNEY, D. E. (Ed.). Organization theory and the multinational corporation. $2^{\text {nd }}$ ed. Houndmills: Palgrave, 2005.

WEAVER, G. R.; GIOIA, D. A. Paradigm lost: incommensurability vs structurationist inquiry. Organization Studies, v.15, n.4, p.565-589, 1994.

WESTNEY, D. E. Institutional theory and the multinational corporations. In: GHOSHAL, S.; WESTNEY, D. E. (Ed.). Organization theory and the multinational corporation. $2^{\text {nd }}$ ed. Houndmills: Palgrave, 2005.

; ZAHEER, S. The multinational enterprise as an organization. In: RUGMAN, A. M.; BREWER, T. (Ed.). The Oxford handbook of international business. Oxford: Oxford University Press, 2001.

WHITE, R. E.; POYNTER, T. A. Strategies for foreign-owned subsidiaries in Canada. Business Quarterly, v.49, n.2, p.611-628, 1984.

WILKINS, Mira. The history of multinational enterprise. In: RUGMAN, A. M.; BREWER, T. (Ed.). The Oxford handbook of international business. Oxford: Oxford University Press, 2001.

${ }^{1}$ Em 2005, Gestão Internacional deixou de ser uma área autônoma no EnANPAD para se tornar uma subárea de Estratégia em Organizações.

${ }^{2}$ Nos EUA, há uma distinção entre os termos management (gestão), normalmente relacionado a atividades no âmbito da administração em empresas privadas, e administration (administração), que usualmente se refere às atividades no âmbito público. Traduções para o português eliminaram tal distinção e, nos últimos anos, a sobreposição dos conceitos fez com que a diferenciação entre ambos se tornasse cada vez mais difícil mesmo em língua inglesa.

${ }^{3}$ Tanto hierarquia quanto heterarquia se referem aqui ao sistema organizacional da corporação (BIRKINSHAW e MORRIS, 1995). No contexto de pesquisa das corporações multinacionais e suas subsidiárias, a idéia subjacente a adoção de hierarquia ou heterarquia é a de "definir um conjunto de atributos contextuais estruturais como o 'nível de autonomia estratégica', que pode ser do 'tipo hierárquico' (baixa autonomia) ou 'tipo heterarquico' (alta autonomia) para uma dada subsidiária. Uma vez que isso tenha sido obtido, será então possível mover-se para o próximo estágio da investigação, que é o de examinar se esses atributos variam significantemente entre os diferentes papéis das subsidiárias". (BIRKINSHAW e MORRIS, 1995, p. 737-738).

${ }^{4}$ Uma tipologia alternativa pode ser encontrada em White e Poynter (1984).

${ }^{5}$ É importante salientar que, no âmbito de Negócios Internacionais, a teoria de custos de transação ofereceu numerosas contribuições para a construção de teorias sobre o processo de tomada de decisão para a internacionalização de empresas (ver RUGMAN; VERBEKE, 2003).

${ }^{6}$ As pressões isomórficas são segundo DiMaggio e Powell (1983): o isomorfismo coercitivo, que resulta de pressões formais e informais externas à organização, exercidas por outras organizações das quais à organização é dependente; o isomorfismo normativo, que é gerado pela profissionalização, envolvendo a criação de normas e métodos de trabalho de um dado segmento ocupacional e, o isomorfismo mimético, que resulta de respostas padronizadas e imitações perante um contexto tomado pela incerteza.

${ }^{7}$ Tradução livre dos autores para a expressão do inglês "taken for granted".

${ }^{8} \mathrm{O}$ estudo das pressões isomórficas normativas nas comunidades epistêmicas, por exemplo, pode oferecer respostas com relação à influência das corporações na produção científica, na definição de tópicos de pesquisas e na formação de profissionais, entre outras questões importantes (DAHAN; DOH; GUAY, 2006). Isso evidencia a influência das corporações por meio de pressões isomórficas no que se refere à criação e disseminação de conhecimento no âmbito da gestão ao redor do mundo, mas que não estão relacionadas especificamente com $\mathrm{Gl}$.

9 Informações a respeito das multinacionais envolvidas e dos objetivos declarados por essa organização podem ser acessadas no endereço eletrônico <www.tabd.com>.

${ }^{10}$ Apesar de a autora permanecer focada na abordagem sociológica. 